\title{
Plant Biotechnology: Past, Present, and Future
}

\author{
John D. Williamson \\ Department of Horticultural Science, North Carolina State University, Raleigh, NC 27695-7609
}

The door to producing genetically engineered plants opened with the seminal discovery by Chilton et al. (1977) that the soil bacterium Agrobacterium tumefaciens caused crown gall disease by transferring a small, defined, plasmid DNA fragment into the plant genome. By 1984 a number of research groups (Bevan et al., 1983; Fraley et al., 1983; Herrera-Estrella et al., 1984) had applied this discovery to create disarmed plasmid vectors which could be used to insert foreign genes into plants. Now, after decades of promise, genetically engineered plant products are finally reaching consumers. So, what took so long? At least four formidable obstacles blocked the way. First, the host range of A. tumefaciens was somewhat limited and did not include a number of important crops such as corn, wheat, etc. Other more flexible gene transfer methods [e.g., Biolistic transformation (Johnston, 1990); or PEG coprecipitation (O'Neill et al., 1993)] now commonly supplement or replace Agrobacteriummediated transformation. Second, inheritance of the foreign gene/ trait requires that germ cells be transformed. To achieve this plants are commonly regenerated from single transformed cells. Unfortunately, regeneration of many elite plant cultivars has proved difficult. Third, too little was known about the molecular, genetic and physiological control of many desired plant traits to allow predictable manipulation. With a few fortuitous exceptions, most transformations proved to be educational rather than marketable. As our mechanistic understanding of plant processes grows, results become more predictable. Finally, the extensive federal, state and local regulations instituted to address concerns about the safety and environmental impact of genetically modified plants must be satisfied (Wilkinson, 1997).

\section{Biotechnology present-Genetically engineered plants in the field}

The first waves of products arising wholly or in part from genetically engineered plants have now reached the consumer. Many more will follow as our knowledge of basic plant processes grows. To provide better perspective on some of these possible future directions in plant genetic engineering, a few of the better known, commercially grown bioengineered crops will be described.

\section{Pathogen-derived viral resistance}

Perhaps the first concrete evidence that plants could be genetically transformed for useful agronomic traits came from the observation by Beachy and colleagues (Abel et al., 1986) that virus disease development was halted or significantly delayed in transgenic plants expressing a tobacco mosaic virus coat protein. Since then many viral sequences have been shown to confer some level of either disease resistance or suppression of disease symptoms (tolerance). Genes that confer viral pathogen-derived resistance (PDR) include those encoding capsid or coat proteins, viral replicase subunits, and viral movement proteins as well as sequences that do not encode proteins, such as defective interfering RNAs and DNAs,

Received for publication 18 Dec. 2001. Accepted for publication 16 Apr. 2002. and nontranslated RNAs (Beachy, 1997; Fitchen and Beachy, 1993). The effectiveness and range of PDR vary widely, and present data are inadequate to establish the precise molecular mechanisms of resistance for most. Nonetheless, in addition to developing disease-resistant plant varieties for agriculture (e.g., Asgrow's Freedom II squash), PDR has increased our understanding of viral pathogenesis and disease. These advances in understanding the fundamental principles underlying resistance and pathogenicity, in turn, will likely lead to second generation genes that confer increased levels of sustainable resistance.

\section{Fruit quality-Antisense technology and the Flavr Savr tomato}

The first commercialized, and perhaps best known, transgenic plant product was Calgene's Flavr Savr tomato, which, after beginning the approval process in February 1989, received final FDA approval on 18 May 1994 (Two Views of the Flavr Savr. "NBIAP News Report." U.S. Department of Agriculture, July 1994). Although something less than a commercial success, the Flavr Savr tomato was the culmination of ground-breaking work begun in the late 1980 s on the regulation of enzymes involved in fruit ripening (Giovannoni et al., 1989; Grierson et al., 1986).

The naturally occurring cell wall component pectin is present in many fruits, including tomatoes, where it serves as a primary determinant of fruit firmness. During ripening, pectin in cell walls is broken down by the enzyme polygalacturonase (PG), whose activity is controlled, at least in part, at the level of gene expression. As the pectin in a tomato's cell walls breaks down the tomato softens, making the ripe fruit difficult to harvest and ship without damage. To address this problem, scientists at Calgene first isolated a PG gene from tomato (Rose et al., 1988). They next converted the tomato PG gene into a reversed or antisense image of itself. This antisense PG construct, called the Flavr Savr gene, was introduced into tomato plants (Sheehy et al., 1988), where its expression interfered with the normal expression of PG. The subsequent reduction in the amount of PG enzyme slows the breakdown of pectin and the resultant fruit softening (Kramer et al., 1990). This produces a firmer ripe fruit and thus allows mechanical harvesting and longer shelf life. Since the introduction of the Flavr Savr tomato, both Pioneer Hi-Bred and DNA Plant Technology Corp. have used conventional breeding methods to produce similar long-shelf-life tomatoes (Super Life and Endless Summer, respectively).

\section{Herbicide tolerance}

Engineering herbicide-tolerant crops was felt to be worthwhile, because their use not only reduces the need for tillage, but also allows smaller, as needed herbicide application during the season, thereby reducing both cost and environmental impact. Monsanto's line of glyphosate-resistant (Round-Up Ready) soybean, corn and cotton is a recent example (See Monsanto's http://www. roundupready.com).

Glyphosate (N-phosphonomethylglycine, Round-Up) is a popu- 
lar, nonselective, broad spectrum, postemergence herbicide with low environmental impact (Malik et al., 1989). Glyphosate kills plants by competitively inhibiting an enzyme required for aromatic amino acid synthesis. Its specific target is the nuclear encoded, chloroplastic enzyme 5-enolpyruvyl-3-phospho-shikimate synthase (EPSPS). Scientists at Monsanto created glyphosate-tolerantEPSPS by engineering the target enzyme to have a lower affinity for glyphosate while retaining normal catalytic activity (Huynh et al., 1988). When reintroduced into plants, this engineered EPSPS conferred glyphosate resistance.

Although all transgenics are extensively tested before their commercial release, there is still concern that the mutant EPSPS genes in these plants could escape through cross-pollination with wild weedy relatives, thus producing herbicide resistant weeds. Use of chloroplast transformation, while technically difficult, would circumvent this problem, because plastid transgenes are not transmitted by pollen. Using a newly developed chloroplast transformation protocol, Daniell et al. (1998) recently succeeded in engineering herbicide resistance by stable integration of a petunia EPSPS gene into the tobacco chloroplast genome. Analysis of $F_{1}$ progeny confirmed stable integration of the EPSPS gene into all of the chloroplast genomes (up to 10,000 copies per cell!), with corresponding gain in glyphosate resistance.

\section{Specialty oils-Laurate canola}

Recent research has linked the trans fatty acid composition of margarine and other foods to increased risk of heart disease and cancer. Coupled with an increased understanding of the biosynthetic pathways involved in production of specific oils, this finding has spurred research on the genetic modification of oil content in plants such as canola (Brassica napus).

One of Calgene's first commercial oil products from this research was LAURICAL (laurate canola) (reviewed in Knauf and Facciotti, 1995), a genetically engineered canola oil containing lauric acid. Laurate (C12) is used in confectionery applications and as a key raw material for soaps and detergents. Currently, commercial sources of laurate are limited to coconut and palm kernel oils imported from Southeast Asia. Calgene has isolated and patented a C12 thioesterase gene responsible for producing laurate. DNA constructs containing this thioesterase gene have been genetically engineered into canola plants, some of which have more than $40 \%$ laurate in the oil. Calgene began commercial sales of its high laurate oil in 1995 and is currently evaluating the functional and commercial value of its laurate canola oil in foods.

Calgene scientists have more recently cloned a $\mathrm{C} 8 / \mathrm{C} 10$ thioesterase gene (Ch FatB2) responsible for producing medium chain fatty acids (MCFA). Expressing Ch FatB2 in transgenic canola, plants that do not normally accumulate any 8:0 or 10:0 MCFA, resulted in plants with up to $28 \%$ MCFA in the oil accompanied by a preferential decrease in the C18 fatty acids, linoleic acid (18:2) and linolenic acid (18:3) (Dehesh et al., 1996). Similar approaches are being applied to modify the nutritional (lipid and protein) composition of other important crops such as peanut, soybean and cacao (for a review Davies, 1996).

\section{Insect resistance-BT toxin}

The Gram-positive bacteria Bacillus thuringiensis (BT) produces one or more types of proteins called delta-endotoxins (Cry and Cyt proteins) localized in parasporal protein inclusion bodies. These proteins are selectively toxic to a large number of insect plant pests.
The intact protein is normally nontoxic, but when ingested, the protein is selectively cleaved by proteases in the gut of target insects. The cleaved protein is an active toxin that binds specific membrane receptors in the insect gut, leading to cell lysis and subsequent insect death by starvation. Since the expression of a truncated CryIA protein in cotton was shown to provide effective protection from the cotton bollworm (Perlak et al., 1990), Monsanto's scientists have engineered several lines of insect resistant plants, including YieldGard corn borer resistant corn, and BollGard boll and bud-worm resistant cotton(see http://www.monsanto.com/monsanto/mediacenter/background/).

As with any single method of insect control, BT is not a magic bullet. The potential for resistance to BT has been recognized since the mid 1980s, with modes of resistance ranging from changes in membrane receptor affinity (Lee et al., 1995) to loss of the gut enzymes involved in cleaving the BT crystal protein (Oppert et al., 1997). Alternate strategies for bioengineering insect resistance being pursued range from expression of insect chitinases, to other bacterially derived toxins. Second generation insect-resistant plants will likely include both BT and non-BT modes of action (reviews by Dempsey et al., 1998 and Estruch et al., 1997). Regardless of the outcome of these ventures, it seems probable that traditional management regimes will still be required.

\section{Biotechnology-The future?}

With the knowledge and experience gained over the last decade in applied and basic plant molecular biology, many possibilities have arisen. New crops have emerged that contain combinations of previously engineered traits. This stacking of tolerance genes allows the introduction of multiple desirable characteristics, such as combined herbicide and insect tolerance, as well as a basis for broader resistance to pests through the introduction of complimentary gene combinations. Finally, greater understanding of basic genetic and metabolic processes should provide the tools necessary for manipulating complex, multistep processes.

\section{Starch content and ADP-glucose pyrophosphorylase}

Altering major metabolic pathways, while potentially useful for modifying many desirable agronomic traits, often produces unintended results. This was dramatically illustrated in experiments aimed at elevating starch content in potatoes for producing highquality potato chips. The plastid-localized enzyme ADP-glucose pyrophosphorylase (ADPGPP) is a key regulator of starch synthesis. The coding sequence for one of the subunits of ADPGPP was linked in the antisense orientation to a cauliflower mosaic virus (CaMV) 35S promoter and introduced into potatoes. The transgenic plants expressed substantially reduced amounts of ADPGPP and had tubers largely devoid of starch (Müller-Röber et al., 1992), thus confirming a likely point for controlling starch production. Engineering plants for increased starch production, however, is potentially a much more complex problem. ADPGPP as well as starch are plastid localized (in chloroplasts of photosynthetic cells and amyloplasts of nonphotosynthetic cells). In addition, plant ADPGPP is a heterotetramer, i.e., composed of two dissimilar subunits. Thus, engineering plants for increased expression of ADPGPP involves the coordinate expression and targeting of two distinct gene products. To further complicate matters, holoenzyme activity is subject to allosteric regulation by both 3-phosphoglycerate (3-PGA; activation) and inorganic phosphate (Pi; inhibition) (Plaxton and Preiss, 1987). 
Stark et al. (1992) used a mutant bacterial ADPGPP to circumvent these problems. The bacterium Escherichia coli makes glycogen, a starch-like polymer, by a pathway analogous to starch biosynthesis, but using a homotetrameric ADPGPP. Also unlike the plant enzyme, bacterial ADPGPP is allosterically activated by fructose 1,6-bisphosphate and inhibited by both adenosine monophosphate (AMP) and Pi. A glycogen overproducing bacteria was found with a mutant form of ADPGPP, glgC16, that was less sensitive than the wild-type gene, $g \lg C$, to both allosteric activators and inhibitors (Stark, et al. 1992, and references therein). When glgC16 was constitutively expressed in potato using the $35 \mathrm{~S}$ promoter and targeted to the chloroplasts using a plastid transit peptide, the resulting excess starch accumulation in chloroplasts resulted in a shortage of sucrose for transport to sinks. This problem was solved by expressing $g \lg C 16$ using the tuber-specific patatin promoter in combination with the plastid transit peptide. These transgenic plants expressed the mutant ADPGPP only in tuber amyloplasts, and produced potatoes with markedly enhanced starch content. Unfortunately, after all this, these potatoes proved unusable, because they were highly susceptible to bruising when normal harvest and grading procedures were used. This bruising may result from the rupture of the high-starch plastids and subsequent release of the plastid-localized enzyme tyrosinase, which promotes the browning reaction. This problem is currently being addressed by researchers at Monsanto to allow commercialization of high starch potatoes.

\section{Resistance to fungal pathogens}

Fungal plant pathogens cause a large number of economically devastating plant diseases. Exact losses are hard to determine, as they not only include losses due to plant mortality and decreased yield, but also higher overhead due to preventative measures employed as well as aesthetic damage that renders plants unmarketable. Although traditional breeding and chemical applications will remain important tools for controlling fungal diseases, each has disadvantages that could be complemented by genetic engineering. Fortunately, several genes recently have been identified that might be suitable for engineering broad fungal resistance.

\section{Ribosome inactivating proteins (RIPs) confer increased fungal resistance}

Plants often employ toxic compounds to either kill invading pathogens or to impede pathogen spread by killing plant cells at the infection site (hypersensitive response). The ribosome-inactivating proteins (RIPs), which disable ribosomal function and thus protein synthesis, have been implicated in both processes. RIP substrate specificity can vary greatly, with some RIPs preferentially disabling mammalian or fungal ribosomes, while others, such as pokeweed antiviral protein (PAP), attack both eukaryotic and prokaryotic ribosomes. As may be deduced from the name, PAP was first identified as an antiviral protein (Bolognesi et al., 1990). However, initial attempts at engineering viral resistance by expressing PAP in transgenic tobacco produced plants with seriously impaired growth (Lodge et al., 1993). Recently, however, Tumer and colleagues expressed nontoxic mutants of PAP in transgenic tobacco (Zoubenko et al., 1997) with surprising results. A PAP gene mutation was made that resulted in a 25 amino acid carboxy-terminal deletion in the encoded protein. The mutant enzyme was nonfunctional, i.e., had lost ribosome-inactivating capacity, so it was not toxic to transgenic plants. As hoped, transgenic plants still showed increased viral resistance. Unexpectedly, transformants also acquired substantial resistance to the fungal pathogen Rhizoctinia solani.

This was unexpected because neither wild type (functional) nor mutant (nonfunctional) PAP is toxic to $R$. solani in culture. The authors hypothesized that the mutant PAP is acting indirectly by inducing general plant defense responses. This hypothesis was supported by the observation that increased fungal resistance correlated with higher expression of a number of plant defense proteins collectively called pathogenesis related (PR) proteins. Expression of either mutant or nonmutant PAP enhanced PR protein expression. However, levels of salicylic acid, an endogenous inducer of PR proteins, were not altered by PAP expression, suggesting that PAP stimulated the plant's defense signal transduction pathway somewhere downstream of salicylic acid. While the precise mechanism of PR gene induction by PAP is unknown, the ribosomal toxicity of PAP clearly is not essential for its participation in defense. Expressing active toxins in a plant is, of course, less than optimal for several reasons. Because PAP toxicity can be separated from its ability to confer pathogen resistance, PAP has potential for engineering disease resistance.

\section{The role of small, cysteine-rich polypeptides in pathogen resistance (thionins and heveins)}

There has been recent interest in genetically engineering fungal resistance in plants through transgenic expression of two groups of small antifungal polypeptides, the heveins and the thionins. Heveins are small cysteine-rich peptides that are homologous to the chitinbinding domains of chitinases and lectins (reviewed by Raikhel et al., 1993). Hevein-like peptides have been identified in Arabidopsis (Potter et al., 1993), citrus (Taylor et al., 1996), sugar beet (Nielson et al., 1997) and Pharbitis nil (Japanese morning glory) (Koo et al., 1998). The thionins are a second group of potent antifungal polypeptides first isolated from radish (Raphanus sativus) (Terras et al., 1992 , 1995). These small ( $\approx 5 \mathrm{kDa}$ ), highly basic, cysteine-rich oligomeric proteins have also been found in several other plants including wheat (Castagnaro et al., 1994), sorghum (Nitti et al., 1995), sugar beet (Kragh et al., 1995) and Arabidopsis (Epple et al., 1995). While constitutive overexpression of thionin coding sequences in tobacco (Carmona et al., 1993) and Arabidopsis (Epple et al., 1997) conferred enhanced resistance to pathogens, additional biological roles have been suggested. In addition to the ability of heveins to bind the chitin in fungal cell walls, both heveins (Koo et al., 1998) and thionins (Florack and Stiekema, 1994) have been reported to disrupt the integrity of fungal membranes. This leads to leakage of cell contents and results in cell death. As with the RIPs, however, engineering pathogen resistance by transgenic expression of toxins, even toxins of reportedly narrow specificity, may be less than ideal.

\section{Nutritional and end-use qualities_-Golden rice}

Although the creation of stacked trait transgenics is becoming more common, the most impressive example to date of a multiple gene transgenic is the production of golden rice varieties by Potrykus and Beyer's group (Ye et al., 2000). Perhaps more significantly, this effort represents a major shift in the use of biotechnology. While previous transgenic efforts have focussed on properties that directly impact production, golden rice, albeit years from field implementation, promises to be the first bioengineered crop to directly benefit the consumer by providing increased nutritional value.

Rice (Oryza sativa) is a major staple in large areas of the world. 
Unfortunately, the part of the rice grain that is eaten, the endosperm, lacks several essential nutrients, most notably $\beta$-carotene, the precursor to vitamin A (provitamin A). As a result, vitamin A deficiency constitutes a serious global health problem. Because of the lack of infrastructure in many affected areas, use of conventional dietary supplements has proven impractical. In addition, because there are no rice cultivars that produce provitamin $\mathrm{A}$ in the endosperm, conventional breeding is not an option. The work of Ye et al. (2000), however, has opened the way for the use of biotechnology in the creation of a rice variety that makes provitamin $\mathrm{A}$.

Developing rice endosperm contains the enzymes that catalyze the initial steps in $\beta$-carotene synthesis. Expression of the genes encoding critical intermediate steps in this pathway, however, is lacking (Burkhardt et al., 1997). To complete the $\beta$-carotene biosynthetic pathway in rice endosperm, cDNA sequences for phytoene synthase ( $p s y$ ) and a lycopene $\beta$-cyclase (lcy) from daffodil (Narcissus pseudonarcissus) together with a sequence encoding a bacterial phytoene desaturase (crtI) from Erwinia uredovora were transformed into rice. Expression of these DNA sequences was under control of the endosperm-specific glutelin $(G t 1)$ and the CaMV $35 \mathrm{~S}$ promoter, respectively, and the resulting enzyme proteins targeted to endosperm plastids, the sites of $\beta$-carotene synthesis. Seeds from some segregating transgenic lines were found to contain $\beta$-carotene as almost the only carotenoid in the endosperm. Levels of $\beta$ carotene in these lines $\left(1.6 \mu \mathrm{g} \cdot \mathrm{g}^{-1}\right)$ appear sufficient to provide a typical Asian rice diet with the daily requirement of provitamin A.

\section{Summary and conclusions}

As with many new technologies, the ability to insert foreign genes into plants has taken decades to translate into potentially viable commercial products. This lag phase in the growth of plant biotechnology now appears to be near an end. The accelerated introduction of new, genetically modified cultivars emanates not just from recent advances in transformation and regeneration technologies, but also from the fact that as we know more about genetic mechanisms and interactions, the manipulation of traits of interest becomes more predictable. Thus, the role of basic research will remain of primary importance. Together with plant biochemistry, genetics and physiology, molecular biology will continue to be an instrument of discovery, laying the groundwork for future biotechnology applications.

Finally, the future success of creating useful, safe, genetically altered plants requires that biotechnologists pool resources with traditional breeders. Close collaborations will allow us to avail ourselves of the decades of genetic and agronomic expertise available, ranging from knowledge of what the real problems are, to designing strategies for breeding newly engineered traits into commercially viable cultivars.

\section{Literature Cited}

Abel, P.P., R.S. Nelson, B. De, N. Hoffmann, S.G. Rogers, R.T. Fraley and R.N. Beachy. 1986. Delay of disease development in transgenic plants that express the tobacco mosaic virus coat protein gene. Science 232:738743.

Beachy, R.N. 1997. Mechanisms and applications of pathogen-derived resistance in transgenic plants. Current Opinions Biotechnol. 1:215-220.

Bevan, M., W.M. Barnes, and M.D. Chilton. 1983. Structure and transcription of the nopaline synthase gene region of T-DNA. Nucleic Acids Res. 11:369-385.

Bolognesi, A., L. Barbieri, A. Abbondanza, A.I. Falasca, D. Carnicelli, M.G. Battelli, and F. Stirpe. 1990. Purification and properties of new ribosome-inactivating proteins with RNAN-glycosidase activity. Biochim. Biophys. Acta. 1087:293-302.

Burkhardt P.K., P. Beyer, J. Wunn, A. Kloti, G.A. Armstrong, M. Schledz, J. von Lintig, and I. Potrykus. 1997. Transgenic rice (Oryza sativa) endosperm expressing daffodil (Narcissus pseudonarcissus) phytoene synthase accumulates phytoene, a key intermediate of provitamin A biosynthesis. Plant J. 11:1071-1078.

Carmona, M., A. Molina, J. Fernandez, J. Lopez-Fando, and F. GarciaOlmedo. 1993. Expression of the alpha-thionin gene from barley in tobacco confers enhanced resistance to bacterial pathogens. Plant J. $3: 457-462$.

Castagnaro, A., C. Marana, P. Carbonero, and F. Garcia-Olmedo. 1994. cDNA cloning and nucleotide sequences of alpha 1 and alpha 2 thionins from hexaploid wheat endosperm. Plant Physiol. 106:1221-1222.

Chilton, M.D., M.H. Drummond, D.J. Merio, D. Sciaky, A.L. Montoya, M.P. Gordon, and E.W. Nester. 1977. Stable incorporation of plasmid DNA into higher plant cells: the molecular basis of crown gall tumorigenesis. Cell 11:263-271.

Daniell, H., R. Datta, S. Varma, S. Gray, and S.B. Lee. 1998. Containment of herbicide resistance through genetic engineering of the chloroplast genome. Nature Biotechnol. 16:345-348.

Davies, H.M. 1996. Engineering new oilseed crops from rapeseed, p. 299306. In: J. Janick (ed.). Progress in new crops. ASHS Press, Alex., Va. Dehesh, K., A. Jones, D.S. Knutzon, and T.A. Voelker. 1996. Production of high levels of 8:0 and 10:0 fatty acids in transgenic canola by overexpression of Ch FatB2, a thioesterase cDNA from Cuphea hookeriana. Plant J. 9:167-172.

Dempsey, D.A., H. Silva, and D.F. Klessig. 1998. Engineering disease and pest resistance in plants. Trends Microbiol. 6:54-61.

Epple, P., K. Apel, and H. Bohlmann. 1995. An Arabidopsis thaliana thionin gene is inducible via a signal transduction pathway different from that for pathogenesis-related proteins. Plant Physiol. 109:813-820.

Epple, P., K. Apel, and H. Bohlmann. 1997. Overexpression of an endogenous thionin enhances resistance of Arabidopsis against Fusarium oxysporum. Plant Cell 9:509-520.

Estruch, J.J., N.B. Carozzi, N. Desai, N.B. Duck, G.W. Warren, and M.G. Koziel. 1997. Transgenic plants: an emerging approach to pest control. Nature Biotechnol. 15:137-141.

Fitchen, J.H. and R.N. Beachy. 1993. Genetically engineered protection against viruses in transgenic plants. Annu. Rev. Microbiol. 47:739-763.

Florack, D.E. and W.J. Stiekema. 1994. Thionins: Properties, possible biological roles and mechanisms of action. Plant Mol. Biol. 26:25-37.

Fraley R.T., S.G. Rogers, R.B. Horsch, P.R. Sanders, J.S. Flick, S.P. Adams, M.L. Bittner,L.A. Brand, C.L. Fink, J.S. Fry, G.R. Galluppi, S.B. Goldberg, N.L. Hoffmann, and S.C. Woo 1983. Expression of bacterial genes in plant cells. Proc. Natl. Acad. Sci. USA 80:4803-4807

Giovannoni, J.J., D. DellaPenna, A.B. Bennett, and R.L. Fischer. 1989. Expression of a chimeric polygalacturonase gene in transgenic rin (ripening inhibitor) tomato fruit results in polyuronide degradation but not fruit softening. Plant Cell 1:53-63.

Grierson, D., G.A. Tucker, J. Keen, J. Ray, C.R. Bird, and W. Schuch. 1986. Sequencing and identification of a cDNA clone for tomato polygalacturonase. Nucleic Acids Res. 14:8595-8603.

Herrera-Estrella, L., G. Van den Broeck, R. Maenhaut, M. Van Montagu, J. Schell, M. Timko, and A. Cashmore. 1984. Light-inducible and chloroplast-associated expression of a chimaeric gene introduced into Nicotiana tabacum using a Ti plasmid vector. Nature 310:115-120.

Huynh, Q.K., S.C. Bauer, G.S. Bild, G.M. Kishore, and J.R. Borgmeyer. 1988. Site-directed mutagenesis of Petunia hybrida 5-enolpyruvylshikimate-3-phosphate synthase: Lys-23 is essential for substrate binding. J. Biol. Chem. 263:11636-11639.

Johnston, S.A. 1990. Biolistic transformation: microbes to mice. Nature 23:776-777.

Knauf, V.C. and D. Facciotti. 1995. Genetic engineering of foods to reduce the risk of heart disease and cancer. Adv. Exptl. Med. Biol. 369:221-228.

Koo, J.C., S.Y. Lee, H.J. Chun, Y.H. Cheong, J.S. Choi, S. Kawabata, M. Miyagi, S. Tsunasawa, K.S. Ha, D.W. Bae, C.D. Han, B.L. Lee, and M.J. Cho. 1998. Two hevein homologs isolated from the seed of Pharbitis 
nil L. exhibit potent antifungal activity. Biochim. Biophys. Acta. 1382:80-90.

Kragh, K.M., J.E. Nielsen, K.K. Nielson, S. Dreboldt, and J.D. Mikkelsen. 1995. Characterization and localization of new antifungal cysteinerich proteins from Beta vulgaris. Mol. Plant Microbe Interact. 8:424434.

Kramer, M.R., R.A. Sanders, R.E. Sheehy, M. Milis, M. Keuhn, and W. Hiatt. 1990. Field evaluation of tomatoes with reduced polygalacturonase by antisense RNA, p. 347-355. In: A.B. Bennett and S.D. O’Neill (eds.). Horticultural biotechnology, plant biology. vol. 11. Wiley-Liss, New York.

Lee. M.K., F. Rajamohan, F. Gould, and D.H. Dean. 1995. Resistance to Bacillus thuringiensis CryIA delta-endotoxins in a laboratory-selected Heliothis virescens strain is related to receptor alteration. Appl. Environ. Microbiol. 61:3836-3842.

Lodge, J.K., W.K. Kaniewski, and N.E. Tumer. 1993. Broad-spectrum virus resistance in transgenic plants expressing pokeweed antiviral protein. Proc. Natl. Acad. Sci. USA 90:7089-7093.

Malik, J., G. Barry, and G. Kishore. 1989. The herbicide glyphosate. Biofactors 2:17-25.

Müller-Röber, B., U. Sonnewald, and L. Willmitzer. 1992. Inhibition of the ADP-glucose pyrophosphorylase in transgenic potatoes leads to sugar-storing tubers and influences tuber formation and expression of tuber storage protein genes. EMBO J. 11:1229-1238.

Nielsen, K.K., J.E. Nielsen, S.M. Madrid, and J.D. Mikkelsen. 1997. Characterization of a new antifungal chitin-binding peptide from sugar beet leaves. Plant Physiol. 113:83-91.

Nitti, G., S. Orru, C. Bloch Jr., L. Morhy, G. Marino, and P. Pucci. 1995. Amino acid sequence and disulfide-bridge pattern of three gammathionins from Sorghum bicolor. Euro. J. Biochem. 228:250-256.

O’Neill, C., G.V. Horvath, E. Horvath, P.J. Dix, and P. Medgyesy. 1993. Chloroplast transformation in plants: polyethylene glycol (PEG) treatment of protoplasts is an alternative to biolistic delivery systems. Plant J. 3:729-738

Oppert, B., K.J. Kramer, R.W. Beeman, D. Johnson, and W.H. McGaughey. 1997. Proteinase-mediated insect resistance to Bacillus thuringiensis toxin. J. Biol. Chem. 272:23473-23476.

Perlak, F.J., R.W. Deaton, T.A. Armstrong, R.L. Fuchs, S.R. Sims, J.T. Greenplate, and D.A. Fischhoff. 1990. Insect resistant cotton plants. Biotechnology 8:939-943.
Plaxton, W.C. and J. Preiss. 1987. Purification and properties of nonproteolytic degraded ADP-glucose pyrophosphorylase from maize endosperm. Plant Physiol. 83:105-112.

Potter, S., S. Uknes, K. Lawton, A.M. Winter, D. Chandler, J. DiMaio, R. Novitzky, E. Ward, and J. Ryals. 1993. Regulation of hevein-like gene in Arabidopsis. Mol. Plant Microbe Interact. 6:680-685.

Raikhel, N.V., H-.I. Lee, and W.F. Broekaert. 1993. Structure and function of chitin-binding proteins. Annu. Rev. Plant Physiol. Plant Mol. Biol. 44:581-615.

Rose, R.E., C.M. Houck, E.K. Monson, C.E. DeJesus, R.E. Sheehy, and W.R. Hiatt. 1988. The nucleotide sequence of the 5' flanking region of a tomato polygalacturonase gene. Nucleic Acids Res. 16:71-91.

Sheehy, R.E., M. Kramer, and W.R. Hiatt. 1988. Reduction of polygalacturonase activity in tomato fruit by antisense RNA. Proc. Natl. Acad. Sci. USA 85:8805-8809.

Stark, D.M., K.P. Timmerman, G.F. Barry, J. Preiss, and G.M. Kishoret. 1992. Regulation of the amount of starch in plant tissues by ADPglucose pyrophosphorylase. Science 258:287-292.

Taylor, K.C., L.G. Albrigo, and C.D. Chase. 1996. Purification of a Znbinding phloem protein with sequence identity to chitin-binding proteins. Plant Physiol. 110:657-664.

Terras, F.R.G., H.M. Schoofs, M.F. De Bolle, F. Van Leuven, S.B. Rees, J. Vanderleyden, B.P. Cammue, and W.F. Broekaert. 1992. Analysis of two novel classes of plant antifungal proteins from radish (Raphanus sativus L.) seeds. J. Biol. Chem. 267:15301-15309.

Terras, F.R.G., K. Eggermont, V. Kovaleva, N.V. Raikhel, R.W. Osborn, A. Kester, S.B. Rees, S. Torrekens, F. Van Leuven, J. Vanderleyden, B.P.A Cammue, and W.F. Broekaert. 1995. Small cysteine-rich antifungal proteins from radish: their role in host defense. Plant Cell 7:573-588. U.S. Department of Agriculture. 1994. Two views of the Flavr Savr. NBIAP news report. USDA, July.

Wilkinson, J.Q. 1997. Biotech Plants: From lab bench to supermarket shelf. Food Technol. 51:37-42.

Ye X., S. Al-Babili, A. Klöti, J. Zhang, P. Lucca, P. Beyer, and I. Potrykus. 2000. Engineering the provitamin A ( $\beta$-carotene) biosynthetic pathway into (carotenoid-free) rice endosperm. Science 287:303305.

Zoubenko, O., F. Uckun, Y. Hur, I. Chet, and N. Tumer. 1997. Plant resistance to fungal infection induced by nontoxic pokeweed antiviral protein mutants. Nature Biotechnol. 15:992-996. 